\title{
Scavenging and metal chelating potential of Carthamus tinctorius L. extracts
}

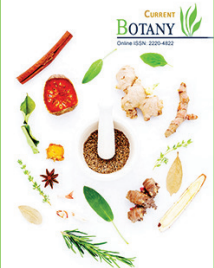

ISSN: $2220-4822$

Received: October 25, 2019

Revised: May 02, 2020

Accepted: May 06, 2020

Published: May 16, 2020

*Corresponding Author:

Ashwini Kumar Dixit

Email:dixitak@live.com

\author{
Rashmi Dehariya, Jagriti Chandrakar, Satish Dubey, Kundan Ojha, \\ Ashwini Kumar Dixit*
}

Laboratory of Molecular Taxonomy and Medicinal Plant Biology, Department of Botany, GuruGhasidas Vishwavidyalaya, Bilaspur 495001, Chhattisgarh, India

\begin{abstract}
Carthamus tinctorius leaves were extracted with methanol and distilled water. The extracts were evaluated for their potential free radical scavenging capacity using four different in vitro methods (DPPH, metal chelation, radical removal and hydrogen peroxide scavenging methods). The total phenolic content obtained for aqueous (112.2 $\pm 1.708 \mathrm{GAE} \mathrm{mg} / \mathrm{g}$ ) and for methanolic extract $(89.66 \pm 2.00 \mathrm{GAE} \mathrm{mg} / \mathrm{g})$. In DPPH IC In values was found to be $176.66 \pm 2.08$ and $278.33 \pm 1.52$ and $310.33 \pm 1.52$ for the ascorbic acid, aqueous and methanolic extract respectively. In superoxide radical scavenging $\mathrm{IC}_{50}$ values are $381.27 \pm 1.43,544.42 \pm 2$ and $606.78 \pm 3.02 \mu \mathrm{g} / \mathrm{ml}$ for the ascorbic acid, aqueous and methanolic extract respectively. In the metal chelating activity, $\mathrm{IC}_{50}$ values are $385.94 \pm 3.00,337 \pm 1$ and $487 \pm 0.984 \mu \mathrm{g} / \mathrm{ml}$ for the EDTA, aqueous extract and methanolic extract respectively. In hydrogen peroxide scavenging $\mathrm{IC}_{50}$ values were $261 \pm 1,278 \pm 3.52$ and $370 \pm 1 \mu \mathrm{g} / \mathrm{ml}$ for the ascorbic acid, aqueous extract and methanolic leaf extract of Carthamus tinctorius respectively. The correlation suggests that phenolic compounds are responsible for the antioxidant activities of leaves.
\end{abstract}

KEYWORDS: Carthamus tinctorius, extract, scavenging, chelating, antioxidant.

\section{INTRODUCTION}

Oxidative stress is generated as a byproduct of the oxidation of various indigenous and exogenous processes [1]. Oxidants like superoxides, hydroxyl radical, peroxyl radicals, hydrogen peroxide etc are some of the common reactive oxygen species and collectively called reactive oxygen species (ROS) [2]. ROS is also responsible for the oxidative damage of biomolecules like lipids, nucleic acid, proteins, amines, deoxyribonucleic acid and carbohydrates. The overproduction of ROS causes many severe diseases such as cancer, ulcerative colitis, neural disorders, cardiovascular disorders and atherosclerosis [3]. The human body is equipped with a range of scavenging enzymes such as Superoxide Dismutase (SOD), Catalase (CAT) and Glutathione (GSH), etc., these defense systems can counteract the deleterious actions of oxidative stress caused by free radicals and protect against cellular and molecular damage. Disruption of this delicate balance between the ROS and the defense system may cause cellular damage.

We live in a world of chemicals that induces oxidative stress by various routes of exposure. In today's life, there is a necessity to take antioxidants to countering them. Synthetic antioxidants available in the market are considered to be unsafe, unstable and also uneconomic. The vegetable is the source of beverages, cosmetics, flavor, fragrances and uses as medicinal material from ancient times [4]. Plants are full of various secondary metabolites which serve as antioxidants. Out of the major class of secondary metabolites (terpenes, phenolics, glycosides and alkaloids) the phenolics are best class to serve as an antioxidant. Phenolic compounds are already reported to have antioxidant, anticarcinogenic, antimutagenic properties [5]. Now it becomes very essential to use natural antioxidants.

There is a need to use more natural antioxidants and also to include natural antioxidants into daily food. Several studies have already reported that phytonutrients derived from the Carthamus tinctorius seeds and flowers and play an amazing role to protect the human body against the life threatening effects by reactive oxygen species [6]. The interest of scientists is now diverting towards the use of natural antioxidants called as active oxygen scavenger [7]. Natural antioxidants are cost effective way to deal with the life threatening effects of free radicals and they are less toxic than synthetic antioxidants [8].

Carthamus tinctorius is a member of Asteraceae or Compositae family. The antioxidative activity of the different parts of plant

Copyright: $\odot$ The authors. This article is open access and licensed under the terms of the Creative Commons Attribution License (http://creativecommons.org/licenses/by/4.0/) which permits unrestricted, use, distribution and reproduction in any medium, or format for any purpose, even commercially provided the work is properly cited. Attribution - You must give appropriate credit, provide a link to the license, and indicate if changes were made. 
like seeds and flowers of Carthamus tinctorius has been already reported [9]. Present work deals with the antioxidative capacity of Carthamus tinctorius leaves extract.

\section{MATERIAL AND METHODS}

\section{Chemicals}

Methanol, 1,1-diphenyl-2-picrylhydrazyl (DPPH), Phenazine methosulfate (PMS), Nicotinamide adenine dinucleotide (NADH), Ethylenediamine tetracetic acid (EDTA), Butylated hydroxyanisole (BHA), Thiobarbaturic acid, ascorbic acid Nitroblue tetrazolium (NBT), Trichloroacetic acid (TCA), tris-hcl buffer, potassium ferricyanide, ferric chloride, ferrous chloride, Butylated hydroxytoluene, phosphate, sodium hydroxide, tris-Hcl buffer, tris buffer, gallic acid, Folin reagent, NADH, NBT, PMS, hydrogen peroxide. All chemicals were purchased from Sigma Aldrich and are of analytical grade.

\section{Plant collection and authentication}

The leaves of plant were collected from the local vegetable market, Koni, Bilaspur, Chhattisgarh and identified by Dr A.K Dixit, Associate professor at the Department of Botany, Guru Ghasidas central university, Bilaspur, Chhattisgarh (voucher number -GGV/BOT/H/AST/DKS/092).

\section{Extraction of Carthamus tinctorius leaves}

The leaves of Carthamus tinctorius were collected and shade dried at room temperature. The dried residues of leaves were ground to a fine powder. A $10 \mathrm{~g}$ of leaves powder was extracted in $100 \mathrm{ml}$ of methanol and distilled water, respectively. These mixtures were kept for 24 hours under the occasional stirring with a shaker at the $30^{\circ} \mathrm{C}$. The extract was filtered with the Whatman filter paper no 1 . The filtrate concentrated using rota-vapor and residue was resuspended in $10 \mathrm{ml}$ methanol and water, respectively and stored at $4^{\circ} \mathrm{C}$ until analysis.

\section{Total phenolic content}

The total phenolic content of leaves extract was determined by the Folin-Ciocalteu method which is described by [10]. Firstly the leaves extract were dissolved in a solvent then the dissolved extracts were mixed with $1.25 \mathrm{ml}$ Folin reagent (diluted 1:10) and sodium carbonate $(7.5 \%)$. The mixture was allowed to incubate at room temperature for $30 \mathrm{~min}$. The absorbance was taken at $765 \mathrm{~nm}$ using a spectrophotometer. The total phenolic content was expressed as gallic acid equivalent per $100 \mathrm{~g}$ of dried plant sample (mg GAE/100).

\section{In vitro antioxidative activity evaluation}

\section{DPPH free radical scavenging activity}

The scavenging activity of Carthamus tinctorius leaves extract and the standard compound BHA was measured using the DPPH method with slight modification [11]. A various concentration of the plant extract was added to $2.9 \mathrm{ml}$ of DPPH $(60 \mu \mathrm{M})$ solution. The reaction of DPPH and antioxidant results in color reduction and this color reduction measured in the form of reducing absorbance at $517 \mathrm{~nm}$ using a UV-VIS Spectrophotometer. The experiment was done in a triplicate. The given formula calculated the inhibition percent of DPPH.

$$
\% \text { inhibition }=\left(A_{0}-A_{1}\right) / A_{0} \times 100
$$

Were A (0) is the absorbance of the control and $A_{(1)}$ is the absorbance of the antioxidant

\section{Superoxide anion scavenging activity}

The superoxide radicals were generated in a mixture of $3.0 \mathrm{ml}$ of Tris HCL buffer (16Mm, pH 8.0). Containing 0.5 ml NBT $(0.3 \mathrm{mM}), 0.5 \mathrm{ml} \mathrm{NADH}$ solution $(0.936 \mathrm{~mm}), 1.0 \mathrm{ml}$ of extract. The reaction was initiated by adding PMS solution to the above mixture. Then the reaction mixture was incubated at $25^{\circ} \mathrm{C}$ for $5 \mathrm{~min}$. The absorbance was measured at $560 \mathrm{~nm}$ in a spectrophotometer against the blank [12]. Decrease absorbance of the reaction mixture shows higher antioxidant activity. The percentage of inhibition of superoxide anion was measured by the formula.

$$
\% \text { inhibition }=\left(A_{0}-A_{1}\right) / A_{0} \times 100
$$

Were $A_{0}=$ absorbance of the control and $A_{1}=$ absorbance of the extract and the standard compound.

\section{Hydrogen peroxide scavenging activity}

The hydrogen peroxide free radical scavenging efficiency of leaves extract was evaluated by following the method of [13]. First, a solution of hydrogen peroxide of $(2 \mathrm{Mmol} / \mathrm{L})$ was prepared in a phosphate buffer of (pH7.4). The sample of plant and standard at different concentrations (125, 250, 500,750, $1000 \mu \mathrm{g} / \mathrm{ml}$ ) were added to the above prepared solution of hydrogen peroxide. After the incubation period of 10 minutes the absorbance of the test sample solution were measured against the blank. The blank solution consists of only phosphate buffer without hydrogen peroxide. The absorbance was taken at $230 \mathrm{~nm}$ to measure the activity of extracts. The percent inhibition was calculated by the formula.

$$
\% \text { inhibition }=\left(A 0 A_{1}\right) / A_{0} \times 100
$$

\section{Metal chelating activity}

The different concentrations of extracts were added to the $1 \mathrm{mM}$ solution of $\mathrm{FeCl}_{2}(0.05 \mathrm{ml})$. The reaction was started by the addition of $0.1 \mathrm{ml}$ ferrozine $(1 \mathrm{~mm})$ then the mixture was shaken very well and left standing at room temperature for $10 \mathrm{~min}$. When the mixture had reached at equilibrium, the absorbance was measured at $562 \mathrm{~nm}$ with the help of spectrophotometer [14]. The ferrozine complex inhibition percentage was calculated by using the following formula.

$$
\% \text { inhibition }=\left(A 0 A_{1}\right) / A_{0} \times 100
$$




\section{Statistical analysis}

The experimental results were expressed as the means \pm SD of three parallel measurements. The results were processed using Microsoft excel 2007 and data were subjected to one way analysis of variance (ANOVA) and significance of difference the between sample means were calculated by Duncans multiple range test using SPSS for windows, standard version 16.0. P- value $<0.05$ was considered as significant and $<0.01$ was considered as highly significant.

\section{RESULTS AND DISCUSSION}

\section{Determination of total phenolic content}

Total phenolic content was measured by using standard gallic acid and results were expressed as gallic acid equivalent (GAE $\mathrm{mg} / \mathrm{ml}$ ). The gallic standard curve was created by plotting concentration versus absorbance and the obtained equation was ( $\mathrm{y}=0.005 \mathrm{x}$ +0.967 ) where $\mathrm{y}$ is absorbance at $760 \mathrm{~nm}$ and $\mathrm{x}$ is concentration. Total phenolic content of aqueous extract and methanolic extract were found to be $112.2 \pm 1.708$ and $89.66 \pm 2.00(\mathrm{GAE} \mathrm{mg} / \mathrm{ml})$ respectively. Standard curve between gallic acid equivalents and absorbance is depicted in (Fig. 1). Remarkably, the aqueous leaves extract contained the high amount of phenolic content

Plant phenolics are best class to serve as an antioxidant $[15,16]$. For the quantification of phenolics, Folin reagent was used which contains phosphomolybdic phosphotungstic acid complex. Phenolic compounds react with this complex, and forms blue color. The absorption was directly proportional to concentration of phenolic compound in the sample. In present investigation, both extracts were found to contain significant level of total phenolic content. A higher level of phenolic content was found in aqueous extract than methanolic extract. This result was consistent with Kruawan and Kangsadalampi (2006) and Kim et al.. (2007) [17,18] who reported that high phenolic content in aqueous extract of C. tinctorius. A high phenolic content were also reported in C. tinctorius flower $[18,19]$. Several other workers suggested that antioxidant activity of plant is correlated with their phenolic content $[20,21,22,23]$.

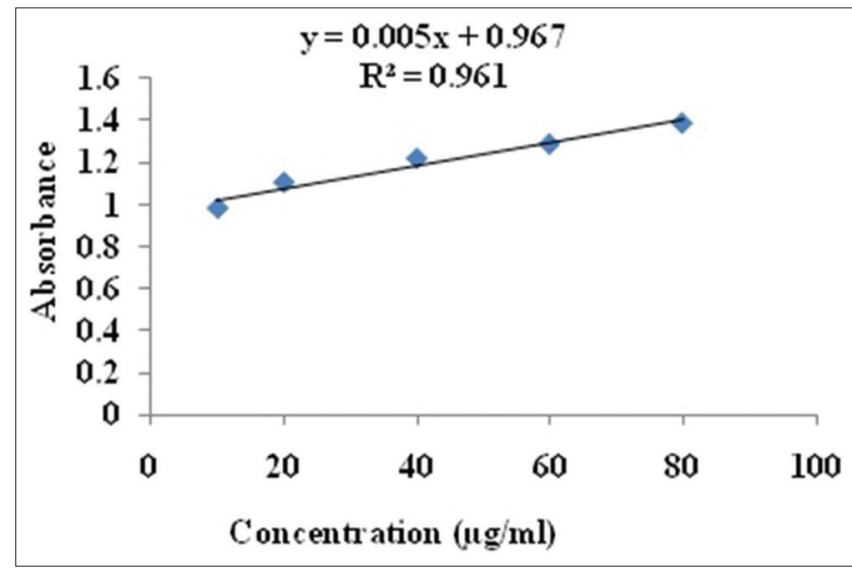

Figure 1: Total phenolic content of $C$. tinctorius expressed in gallic acid equivalents (mg GAE/g)

\section{Determination of in vitro antioxidant potential of} Carthamus tinctorius leaves extract

\section{DPPH free radical scavenging activity}

A stable free radical DPPH accepts an electron or hydrogen atom to become a stable diamagnetic molecule [24]. Carthamus tinctorius leaves extract showed efficient DPPH scavenging activity. The IC 50 values were found to be $176.66 \pm 2.08$ and $278.33 \pm 1.52$ and $310.33 \pm 1.52$ for the ascorbic acid, aqueous and methanolic extract respectively.

The DPPH scavenging activity of standard BHT at the concentration $(125,250,500,750,1000 \mu \mathrm{g} / \mathrm{ml})$ was found to be $74 \pm 0.57,76.33 \pm 0.52,78 \pm 0.57,83.00 \pm 1.00,84.32 \pm 1.52 \%$ respectively. The DPPH activity of aqueous extract at the same concentration $(125-1000 \mu \mathrm{g} / \mathrm{ml})$ was found to be $45.0 \pm 2.08$, $56.00 \pm 2.03,68.78 \pm 1.00,70 \pm 1.00,88.00 \pm 1.53$. Scavenging activity of methanolic extract at same concentration $(125-1000 \mu \mathrm{g} / \mathrm{ml})$ was found to be $26.26 \pm 1.53,59.0 \pm 1.52$, $61.00 \pm 1.0,86.0 \pm 1.0$ and $87.0 \pm 1.52$ respectively (Fig. 2). The $\%$ inhibition at lower concentration of plant extracts were found to be significant (ANOVA, Tukey, at $P<0.05$ ). As concentration increase up to $1000 \mu \mathrm{g} / \mathrm{ml}$ the inhibition percentage between all three tested variable was found to be null (ANOVA, Tukey, at $P>0.05$.

DPPH is a common method used to estimate the antioxidant activity of natural or synthetic compounds. DPPH is a stable free radical and accepts electron or hydrogen atom to become a stable diamagnetic molecule $[25,26,27]$. This method is based on the reaction of DPPH with hydrogen donors of antioxidant compounds of plant which results in stable product. The reduction of DPPH in the presence of antioxidant becomes visible when its color changes from purple to yellow [28,29,30]. The intensity of yellow color is directly proportional to scavenging capacity of plant extract and standard. The percent inhibition

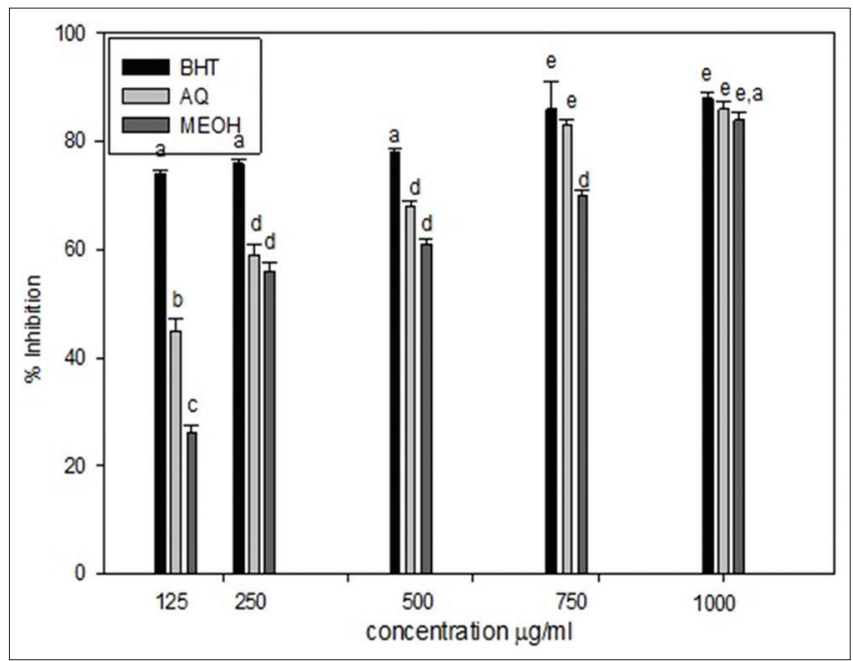

Figure 2: Antioxidant activity of $C$.tinctorius using the DPPH method at different concentrations. Results are mean \pm SD of three parallel measurements, $P$-value $\leq 0.01$. Different letters show significant variation and the same letters shows homogeneity of the data set 
was increased with increase in the concentration of extracts. Both aqueous and methanolic extracts showed remarkable scavenging of DPPH. The standard antioxidant BHT control showed maximum scavenging of DPPH radical than aqueous and methanolic plant extract. But when we compared scavenging potential at higher concentration $(1000 \mu \mathrm{g} / \mathrm{ml})$ scavenging potential of plant extracts were found to be almost equal to synthetic antioxidant (BHT) $(P>0.05)$. Therefore, if we take this leafy vegetable with water in appropriate dose then it might be serves as better antioxidant then synthetic one. Moreover, high scavenging activity of aqueous leaf extract than methanolic leaves extract is may be due to the presence of more water soluble antioxidant compounds in leaves [17]. These finding are consistent with Kusoglu and Kahraman, (2015) [31] who also found leaf extract of $C$. tinctorius was effective scavenger of superoxide and DPPH radicals. Some other part like seed extract of C. tinctorius reported to have high DPPH scavenging activity in some independent studies [17,18,32,33].

\section{Superoxide anion scavenging activity}

In the PMS/NADH-NBT system, superoxide radicals are generated by the coupling of PMS/NADH. The oxidation reaction of NADH results in the superoxide radical production; this is measured by the NBT reduction. The generation of PMS - NADH takes place non enzymatically. Superoxide anion is generated from the dissolved oxygen. At $560 \mathrm{~nm}$ activity was measured and a decrease in the concentration of superoxide anion was recorded because the increase in the concentration of plant extract causes a decrease in the consumption of superoxide anion. Superoxide decomposition is evident to forms a powerful oxidative species like singlet oxygen and hydroxyl radicals [34]. The IC50 values are $381.27 \pm 1.43,544.42 \pm 2$ and $606.78 \pm 3.02 \mu \mathrm{g} / \mathrm{ml}$ for the ascorbic acid, aqueous and methanolic extract respectively. Less is the IC 50 value, more effective is an antioxidative agent.

During assay, it was observed that C. tinctorius leaves extract $(125-1000 \mu \mathrm{g} / \mathrm{ml})$ able to reduce the formation of blue NBT due to which superoxide radical inhibition takes place. The radical scavenging activity of standard ascorbic acid at the concentration $(125,250,500,750,1000 \mu \mathrm{g} / \mathrm{ml})$ was found to be $60.33 \pm 2.08,63.33 \pm 1.52,76.66 \pm 1.15,86.00 \pm 1.00$ $92.33 \pm 1.52 \%$ respectively. The scavenging activity of aqueous extract at the same concentration in terms of percent inhibition was found to be $26.00 \pm 1.00,34.00 \pm 0.03,51.78 \pm 0.69$, $65.33 \pm 1.52,85.00 \pm 1.00$ respectively. Scavenging activity of methanolic extract at the same concentration was found to be $10.26 \pm 0.64,26.00 \pm 1.00,42.00 \pm 1.00,61.00 \pm 1.00$ and $80.00 \pm 1.00$ respectively. As shown in (Fig. 3), as leaf extract concentration was increases the $\%$ inhibition was also increases $($ all $\mathrm{p}<0.05)$. The standard showed maximum radical scavenging activity. However, aqueous extract shows significantly more activity than methanolic extract at lower concentration (all $\mathrm{p}<0.05)$.

Superoxide radical are abundantly found in aerobic systems. These radicals generates destructive species e,g. hydroxyl radical due to which pathogenesis of many diseases and

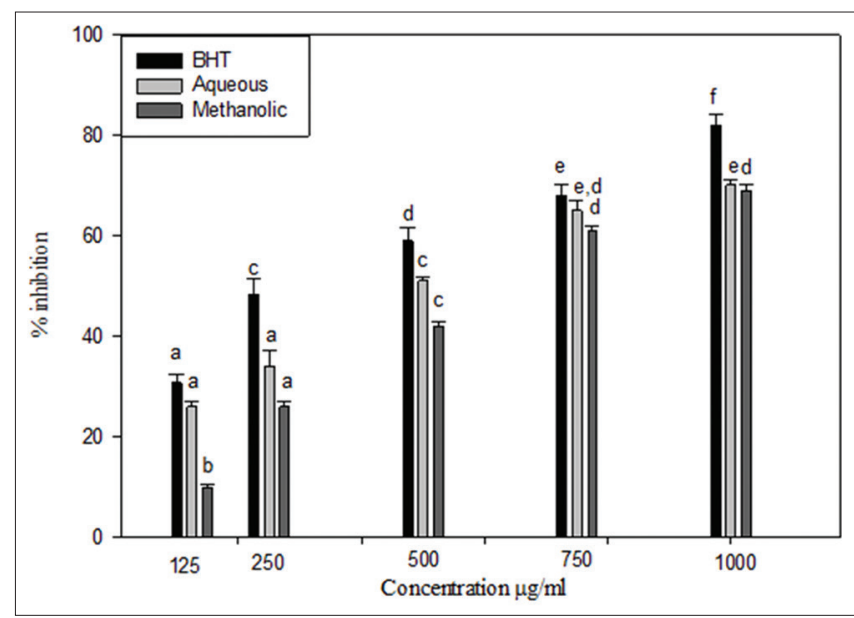

Figure 3: Antioxidative activity of $C$.tinctorius using superoxide radical scavenging. Results are mean \pm SD of three parallel measurements, $P$-value $\leq 0.01$. Different letters show significant variation and same the letters shows homogeneity of the data set

lipid peroxidation takes place $[35,36,37]$. Moreover, inactivation of different iron-sulfur containing enzymes due to superoxide radicals is the leading cause of several metabolic disorders $[38,15,39,40]$. Superoxide radical scavenging assay is based on the reduction potential of plant extract due to which yellow dye nitrobluetetrazolium is reduced into formazan. Formazan is a free radical which is generated when phenazinemethosulphate reacts with nicotinamide adenine dinucleotide, these generated ions reduce NBT into tetrazolium. The reduction of NBT to tetrazolium was determined at $560 \mathrm{~nm}$. A significant reduction in the concentration of superoxide was found when concentration of plant extract and standard were increased. Therefore, percent inhibition was also increased with concentration of extracts. In present study, significantly higher level of free radical (superoxide) scavenging were found in standard antioxidant ascorbic acid as compared to both extracts (all p<0.005). However, aqueous leaf extract shows higher level of scavenging than methanolic leaf extract which is may be due to the presence of more water soluble superoxide scavenging antioxidant compounds in leaf. But when we compared superoxide scavenging potential at higher concentration $(1000 \mu \mathrm{g} / \mathrm{ml})$ scavenging potential of both extracts (methanolic and aqueous) were found to be almost equal (All $\mathrm{p}>0.05)$. Which is may be due to saturation of antioxidants in a solvent. The results obtained from this study concurred with the findings of Kusoglu and Kahraman, (2015) [31] they also found leaves extract of $C$. tinctorius were the effective scavenger of superoxide radicals. Another result given by Mandade et al.. (2011) [32] supports this finding and stated that aerial part of safflower significantly scavenges superoxide radical. Our results are contrast with Kim et al.. (2000) [4l] who found high $\mathrm{IC}_{50}$ value against superoxide radical.

\section{Metal chelating}

Ferrozine forms a complex with $\mathrm{Fe}^{2+}$ while the presence of other chelating agents disrupts the formation of the complex due to which, the red color of the complex decreases, this 
decrease in the red color measured at $562 \mathrm{~nm}$. This red color reduction is the estimation of the presence of another chelating agent [42]. The significatory effect of metal chelating activity is to slow down the lipid peroxidation by reducing the concentration of transition metal ions. Metal chelators stabilized the oxidized form of the metal ion by reducing the redox potential and worked as a secondary antioxidant. In the process of lipid peroxidation, the presence of transition metal decreases significantly by the metal chelating activity. In the present study, the decrease in the intensity of the red color is may be due to the presence of metal chelating agents present in the leaves extract were observed so it can be assumed that Carthamus tinctorius leaves extract have been disrupt the ferrozine $-\mathrm{Fe}^{2+}$ complex. However, this chelating activity was lower than the EDTA. This color reduction was quantitatively measured by a spectrophotometer at $562 \mathrm{~nm}$. The IC 50 values are $385.94 \pm 3.00,337 \pm 1$ and $487 \pm 0.984 \mu \mathrm{g} / \mathrm{ml}$ for the EDTA, aqueous extract and methanolic extract respectively.

The metal chelating activity obtained for standard compound EDTA in the form of percent inhibition was found to be $56.66 \pm 1.08,65.00 \pm 1.52,78.66 \pm 1.15,80.00 \pm 1.00$, $94.00 \pm 1.52$ at the concentration of $125,250,500,750$, $1000 \mu \mathrm{g} / \mathrm{ml}$ respectively (Fig. 4). Metal chelating of aqueous extract $(125-1000 \mu \mathrm{g} / \mathrm{ml})$ was found to be $28.00 \pm 1.00$, $35.00 \pm 1.52,52.00 \pm 0.689,60.33 \pm 2.00,87.00 \pm 1.00$. Metal inhibition percent of methanolic extract at same concentration was found to be $15.26 \pm 0.64,30.00 \pm 1.00,44.00 \pm 1.00$, $58.00 \pm 1.00$ and $84.00 \pm 1.00$.

Bivalent metal ions are important part of many oxidative processes, their catalyst properties generates hydroxyl radical and hydrogen peroxide through Fenton reaction. Minimization of transition metal ion is very essential because, it has the ability to produce free radicals $[43,44,45]$. Therefore we investigated metal chelating activity of C. tinctorius. For quantification of chelating agent Ferrozine chemical was

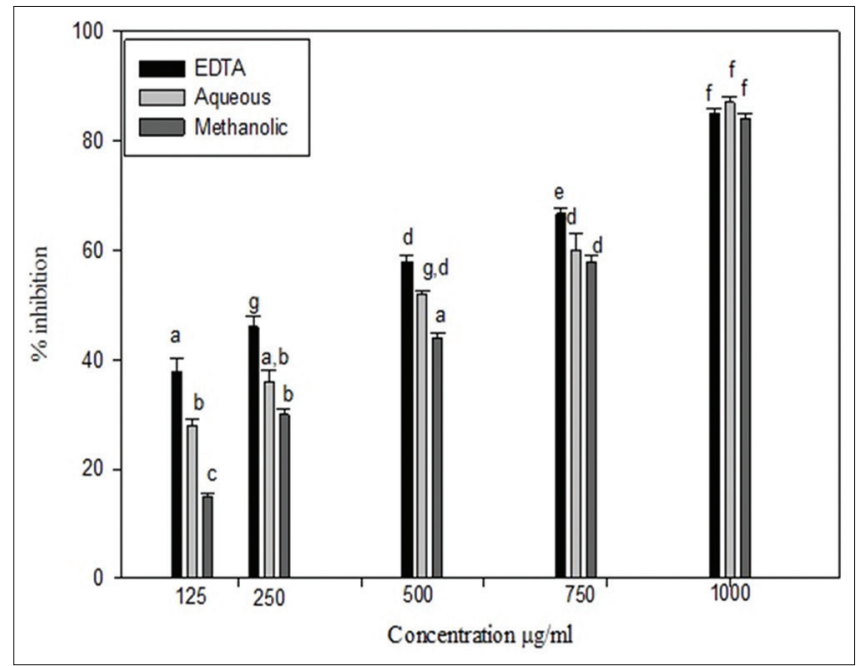

Figure 4: Antioxidative activity of $C$. tinctorius using metal chelating activity. Results are mean \pm SD of three parallel measurements, $P$ - value $\leq 0.01$. Different letters show significant variation and the same letters show homogeneity of the data set used. This chemical forms complex in the presence of other chelating agents and form red color [15]. If chelating agent present in the plant extract they inhibits the formation of ferrozine-metal ion complex. Hence, reduction in intensity of red colour takes place. Aqueous extract showed higher metal chelating activity than methanolic extract. It is mentioned in earlier reports that chelating agents are effective as secondary antioxidants because, they decrease the redox potential and therefore stabilizing the redox form of the metal ion. It might be possible that secondary metabolites present in leaf extract of C. tinctorius responsible for increases in the metal chelating activity of extracts.

\section{Hydrogen peroxide scavenging activity}

Hydrogen peroxide forms hydroxyl radicals by the process of lipid peroxidation and causes DNA damages [46]. The IC 50 values were $261 \pm 1,278 \pm 3.52$ and $370 \pm 1$ for the Ascorbic acid, aqueous extract and methanolic leaf extract of Carthamus tinctorius respectively.

The peroxide activity in the form of percent inhibition was found to be $74.00 \pm 1.00,78.00 \pm 1.00,85.00 \pm 1.00,90.00 \pm 1.00$, $94.00 \pm 1.52$ at the concentration of $125,250,500,750$, $1000 \mu \mathrm{g} / \mathrm{ml}$ respectively using BHT (Butylatedhydroxy anisole) as standard. At the same concentration $(125-1000 \mu \mathrm{g} / \mathrm{ml})$ hydrogen peroxide activity for aqueous extract was found to be $36.66 \pm 1.52,50.00 \pm 1.00,56.33 \pm 0.57,73.66 \pm 0.57$, $85.00 \pm 1.00$, and for methanolic extract it was found to be $5.80 \pm 0.98,22.33 \pm 1.65,26.00 \pm 0.35,46.33 \pm 2.00$, $67.00 \pm 1.00$. The hydrogen peroxide scavenging activity is shown in (Fig. 5).

Hydrogen peroxide is a byproduct of different free radical mechanism. It inactivates many enzymes by oxidation of thiol groups and due to its permeability to cell membranes it is able to oxidize cell compounds $[47,48]$. Due to high reactivity of hydrogen peroxides with metal ions e.g. copper and iron

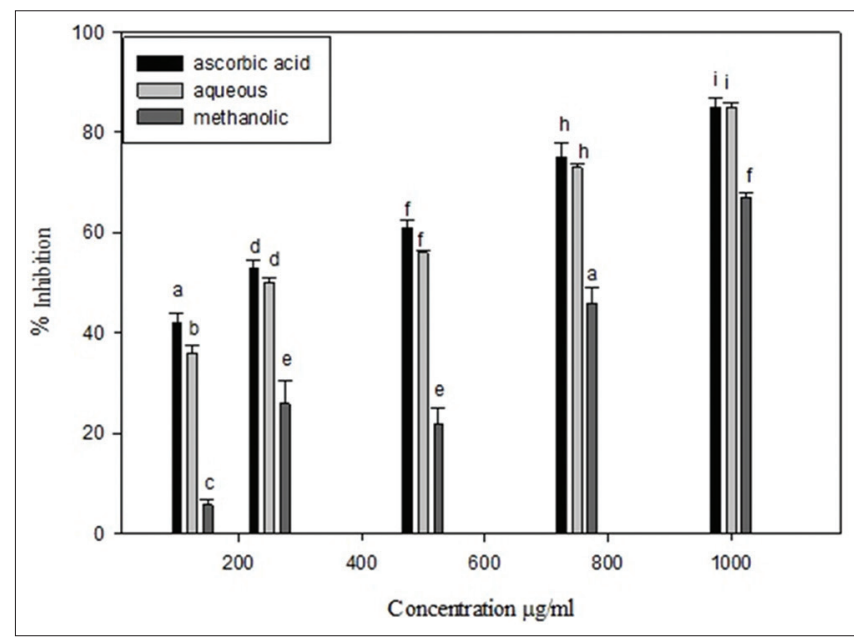

Figure 5: Antioxidant activity of $C$. tinctorius using hydrogen peroxide assay. Results are mean $\pm S D$ of three parallel measurements, $P$ value $\leq 0.01$. Different letters show significant variation and same the letters shows homogeneity of the data set 
hydroxyl radicals are generates. Peroxide radical is the source of lipid peroxidation and causes DNA damages [49,50,51,52]. Like catalase enzyme this leaf extract of $C$. tinctorius were significantly reduced the level of hydrogen peroxide. Moderately lower activity of methanolic extract was observed than aqueous extract. This may be due to lower polyphenolic concentration found in methanolic extract. The results obtained from this study corroborated with Mandade et al.. (2011) [32] who found significant hydrogen peroxide scavenging activity $(63.9 \%)$ at the concentration of $20 \mu \mathrm{g} / \mathrm{ml}$ from the aerial part of safflower. Our results are also in agreement with Ye et al.., (2008) [53] in which water extract of C. tinctorius leaf efficiently lowers the LDH, MDA, $\mathrm{XOD}$ and ROS mediated signals and helps in antioxidative response. Phenolic compounds terminate the chain of free radicals by virtue of donating hydrogen atoms [54]. Phenolic compounds also act as metal chelator [55]. Enzymes involved in free radical generation such as cytochrome P450 isoform, lipoxygenase, cyclooxygenase and xanthine oxidase are inhibited in presence of phenolic compounds [56]. Synergistic effect is also takes place between phenolics and other antioxidants like ascorbic acid, $\beta$-carotene and $\alpha$-tocopherol [57].

\section{Correlations between the antioxidative activities and total phenolic content}

Furthermore, quantitative analysis was also used to know the correlation between antioxidant activities and phenolic content in different extracts. The correlation between total phenolic content and DPPH, superoxide radical scavenging, metal chelating and hydrogen peroxide scavenging assay obtained for aqueous extract $\left(\mathrm{R}^{2}=0.942\right),\left(\mathrm{R}^{2}=0.983\right),\left(\mathrm{R}^{2}=0.963\right)$ and $\left(\mathrm{R}^{2}=0.950\right)$ respectively. The correlation between total phenolic content and DPPH, superoxide radical scavenging, metal chelating and hydrogen peroxide scavenging for methanolic extract $\left(R^{2}=0.861\right),\left(R^{2}=0.983\right),\left(R^{2}=0.963\right)$ and $\left(R^{2}=0.950\right)$ respectively. Suggesting that phenolic compounds are might be responsible for the antioxidant potential of C. tinctorius leaves. The excellent correlation also infers that a large class of compounds responsible for the antioxidative potential of the $C$. tinctorius leaves were belongs to phenolics. The basis for phenolic compounds to work as an antioxidant is hidden into their structure. Structurally phenolics are composed of two or more aromatic rings in which two or more hydroxyl groups are present and because of these phenolics can scavenge the free radicals by forming resonance-stabilized phenoxyl radicals [58]. As indicated in (Table 1) the correlation obtained by comparison of TPC and antioxidant activity revealed that highest positive correlation of TPC was found with superoxide scavenging followed by metal chelating then with hydrogen peroxide. The lowest correlation was found between TPC and DPPH. In both extracts same frequency of correlation was observed. Present results conferred that phenolic compounds are might be responsible for the antioxidant potential of C.tinctorius leaves. Comparatively aqueous extract was more significantly $(P<0.01)$ correlated with antioxidant activity.
Table 1: Correlation between antioxidant activity and total phenolic content

\begin{tabular}{lcccc}
\hline Type of solvent & DPPH & $\begin{array}{c}\text { Superoxide } \\
\text { scavenging } \\
\text { activity }\end{array}$ & $\begin{array}{c}\text { Metal } \\
\text { chelating }\end{array}$ & $\begin{array}{c}\text { Hydrogen } \\
\text { peroxide } \\
\text { scavenging }\end{array}$ \\
\hline TPC(aqueous extract) & $0.94 * *$ & $0.98 * *$ & $0.96 * *$ & $0.95 * *$ \\
TPC(methanolic extract) & $0.86 *$ & $0.97 * *$ & $0.96 * *$ & $0.88^{*}$ \\
\hline
\end{tabular}

TPC: Total Phenolic Content; ${ }^{*}: p<0.05 ; * *: p<0.01$

\section{CONCLUSION}

Plants are utilized for restorative reason since a long time ago. The relationship between plant and human society is very old and intimate. Ayurveda or science of life is a very old system which is evolved from the therapeutic employments of plant. Medicinal plants have different secondary metabolites which are known as phytoactives. These phytoactives chemicals have high reduction potential therefore these chemical behaves as strong antioxidant because they scavenge free radicals. In the present study, C. tinctorius leaves which are also used in diet were analyzed in terms of their antioxidative potential and total phenolic content. Statistically significant differences were observed among the different assays and different extracts. In terms of antioxidative activity, aqueous extract of plant showed higher potential than the methanolic extract. The phenolics are the main phytocompounds responsible for the antioxidative activity (evidenced by good correlation). Further isolation of responsible agents for the activity and in vivo studies are required. Overall, C. tinctorius leaves with water might be used as an antioxidant. The percent inhibition was found to be concentration dependent.

\section{ACKNOWLEDGEMENTS}

UGC, Rajeev Gandhi National Fellowship supported the work.

\section{CONFLICT OF INTEREST}

Author's show no conflict of interest.

\section{REFERENCES}

1. Mathew, S and Abraham, E. (2006) Studies on the antioxidant activities of Cinnamon (Cinnamomum verum) bark extracts, through various in vitro models. Food chemistry, 94, 520-528.

2. Ahmad, P., Sarwat, M. and Sharma, S. (2008) Reactive oxygen species, antioxidants and signaling in plants. Journal of Plant Biology, 51, 3, 167-173.

3. Gouveia- Figueira, S.C., Gouveia, C.A., Carvalho, M.J., Rodrigues, A.I., Nording, M.L. and Castilho, P.C. (2014). Antioxidant capacity, cytotoxicity and antimycobacterial activity of Madeira Archipelago endemic helichrysum dietary and medicinal plants. Antioxidants, 3, 713-729.

4. Nantitanon, W., Yotsawimonwat, S. and Okonogi, S. (2010). Factors influencing antioxidant activities and total phenolic content of guava leaf extract. LWT- Food Science and Technology, 43, 1095-1103.

5. Moldovan, Z., Buleandra, M., Operea, E. and Minea, Z. (2017). Studies on chemical composition and antioxidant activity of Rudbeckia tribola. Journal of Analytical Methods in Chemistry. https.//doi. org/10.1155/2017/3407312.

6. Akihisa,T., Yasukawa K.,Oinuma H., Kasahara Y., Yamanouichi S., Takido M., Kumaki K \& Tamura T.(1996).Triterpine alcohols from 
the flower of compositae and their anti inflammatory effects. Phytochemistry, 6,1255-1260.

7. Kasote, D.M., Katyare, S.S., Hegde, M.V., Bae, H. (2015). Significance of antioxidant potential of plants and relevance to therapeutic applications. International journal of Biological science. 11(8), 982- 991.

8. Ojha, K., Dubey, S., Chandrakar, J., Minj, R. A., Dehariya, R. and Dixit, A. K. (2018). A review on different methods of determination of antioxidant activity assay of herbal plants. Life Science Informatics Publications, 4(6), 707-730.

9. Dehariya, R. \& Dixit, A.K. (2015). A review on potential pharmacological uses of Carthamus tinctorius L. World journal of pharmaceutical science,3(8), 1741-1746.

10. Zheng, W., Wang, S. Y. (2001). Antioxidant activity and phenolic compounds in selected herbs. Journal of Agriculture and food chemistry, 49, 5165-5170

11. Soares, J.R., Dins, T.C.P., Cunha, A.P. \& Ameida,L. M. (1997) Antioxidant activity of some extracts of thymus zygis. Free radical research, 26:469-478.

12. Korycka-Dahl, M. and Richardson, M. (1978). Photogeneration of superoxide anion in serum of bovine milk and in model systems containing riboflavin and amino acids. Journal of Dairy Science. 61.

13. Ruch, R.J., Cheng, S.J., and Klaunig, J.E. (1989).Prevention of cytotoxicity and inhibition of intracellular communication by antioxidant catechins isolated from Chinese green tea. Carcinogenesis, 10, 1003-1008

14. Dinis, T.C.P., Madeira, V.M.C. \& Almeida, L.M. (1994). Action of phenolic derivatives (acetaminophen, salycilate and 5-aminosalycilate) as inhibitors of membrane lipid peroxidation and as peroxyl radical scavengers. Archives of Biochemistry and Biophysics, 315, 161-169.

15. Gulçin, İ., Huyut, Z., Elmastaş, M., \& Aboul-Enein, H. Y. (2010). Radical scavenging and antioxidant activity of tannic acid. Arabian Journal of Chemistry, 3(1), 43-53.

16. Embuscado, M. E. (2015). Spices and herbs: Natural sources of antioxidants-a mini review. Journal of functional foods, 18, 811-819.

17. Kruawan, K., \& Kangsadalampai, K. (2006). Antioxidant activity, phenolic compound contents and antimutagenic activity of some water extract of herbs. Thai Journal of Pharmaceutical Science, 30 , 28-35.

18. Kim, E. O., Oh, J. H., Lee, S. K., Lee, J. Y., \& Choi, S. W. (2007). Antioxidant properties and quantification of phenolic compounds from safflower (Carthamus tinctorius L.) seeds. Food Science and Biotechnology, 16(1), 71-77.

19. Salem, N., Msaada, K., Hamdaoui, G., Limam, F., \& Marzouk, B. (2011). Variation in phenolic composition and antioxidant activity during flower development of safflower (Carthamus tinctorius L.). Journal of Agricultural and Food Chemistry, 59(9), 4455-4463.

20. Javanmardi, J., Stushnoff, C., Locke, E., \& Vivanco, J. M. (2003). Antioxidant activity and total phenolic content of Iranian Ocimum accessions. Food chemistry, 83(4), 547-550.

21. Meda, A., Lamien, C. E., Romito, M., Millogo, J., \& Nacoulma, O. G. (2005). Determination of the total phenolic, flavonoid and proline contents in Burkina Fasan honey, as well as their radical scavenging activity. Food chemistry, 91(3), 571-577.

22. Leelarungrayub, N., Rattanapanone, V., Chanarat, N., \& Gebicki, J. M. (2006). Quantitative evaluation of the antioxidant properties of garlic and shallot preparations. Nutrition, 22(3), 266-274.

23. Torkornoo, D. (2018). Evaluation of the anti-proliferative effect, antioxidant and phytochemical constituents of Ficus pumila Linn (Doctoral dissertation).

24. Bursal, E. and Gulcin, I. (2011). Polyphenol content and in vitro antioxidant activities of lyophilized aqueous extract of kiwifruit (Actinidia deliciosa). Food research international,44, 1482-1489.

25. Yan, X., Nagata, T., \& Fan, X. (1998). Antioxidative activities in some common seaweeds. Plant Foods for Human Nutrition, 52(3), 253-262.

26. Kedare, S. B., \& Singh, R. P. (2011). Genesis and development of DPPH method of antioxidant assay. Journal of food science and technology, 48(4), 412-422.

27. Silva, K. D. R. R., \& Sirasa, M. S. F. (2018). Antioxidant properties of selected fruit cultivars grown in Sri Lanka. Food chemistry, 238, 203-208.

28. Yamaguchi, T., Takamura, H., Matoba, T., \& Terao, J. (1998). HPLC method for evaluation of the free radical-scavenging activity of foods by using 1, 1-diphenyl-2-picrylhydrazyl. Bioscience, Biotechnology, and Biochemistry, 62(6), 1201-1204.

29. Venant, N., He, Q., He-ya, W. A. N. G., Jun-jie, C. H. E. N., and Qingrong, L. I. A. N. G. (2004). Evaluation of Antioxidant Activity of Psidium guajava Linn (Guava) Leaf Extracts by Means of DPPH Free Radical [J]. Food Science, 7.

30. Musa, K. H., Abdullah, A., \& Al-Haiqi, A. (2016). Determination of DPPH free radical scavenging activity: application of artificial neural networks. Food Chemistry, 194, 705-711.

31. Kuşoğlu, E., \& Kahraman, S. (2015). Total Phenolic Content and Radical Scavenging Activity of Carthamus tinctorius L. Internationa Journal of Electronics, Mechanical and Mechatronics Engineering, 5(2), 943-947.

32. Mandade, R., Sreenivas, S. A., \& Choudhury, A. (2011). Radical scavenging and antioxidant activity of Carthamus tinctorius extracts. Free Radicals and Antioxidants, 1(3), 87-93.

33. Hwang, E. Y., Kim, D. H., Kim, H. J., Hwang, J. Y., Park, T. S., Lee, I. S., and Son, J. H. (2011). Antioxidant activities and nitric oxide production of medicine plants in Gyeongsangbukdo (Carthamus tinctorius seed, Cyperus rotundus, Schizonepeta tenuifolia, Polygonatum odoratum var. Pluriflorum, Paeonia lactiflora). Journal of Applied Biological Chemistry, 54(3), 171-177.

34. Tuba, A.K. and Gulcin, I. (2008). Antioxidant and radical scavenging properties of Curcumin. Chemico-Biological Interactions. 174, 27-37.

35. Fridovich, I. (1995). Superoxide radical and superoxide dismutases. Annual review of biochemistry, 64(1), 97-112.

36. Sam, C. H., \& Lu, H. K. (2009). The role of hypochlorous acid as one of the reactive oxygen species in periodontal disease. Journal of Dental Sciences, 4(2), 45-54.

37. Das, K., \& Roychoudhury, A. (2014). Reactive oxygen species (ROS) and response of antioxidants as ROS-scavengers during environmental stress in plants. Frontiers in Environmental Science, 2, 53.

38. Kehrer, J. P. (1993). Free radicals as mediators of tissue injury and disease. Critical reviews in toxicology, 23(1), 21-48.

39. Khan, R. A., Khan, M. R., Sahreen, S., \& Ahmed, M. (2012). Evaluation of phenolic contents and antioxidant activity of various solvent extracts of Sonchus asper (L.) Hill. Chemistry Central Journal, 6(1), 12

40. Islam, M. T. (2017). Oxidative stress and mitochondrial dysfunctionlinked neurodegenerative disorders. Neurological research, 39(1), 73-82.

41. Kim, H. J., Jun, B. S., Kim, S. K., Cha, J. Y., and Cho, Y. S. (2000) Polyphenolic compound content and antioxidative activities by extracts from seed, sprout and flower of safflower (Carthamus tinctorius L.). Journal-Korean Society Of Food Science And Nutrition, 29(6), 1127-1132.

42. Alam, M.D., Bristi, N.J. and Rafiquzzaman, M.(2013). Review on in vivo and in vitro methods eavaluation of antioxidant activity. Saudi pharmaceutical journal,2(2), 143-152.

43. Cheng, I. F., \& Breen, K. (2000). On the ability of four flavonoids, baicilein, luteolin, naringenin, and quercetin, to suppress the Fenton reaction of the iron-ATP complex. Biometals, 13(1), 77-83.

44. Wei, Y., \& Guo, M. (2007). Hydrogen peroxide triggered prochelator activation, subsequent metal chelation, and attenuation of the fenton reaction. Angewandte Chemie International Edition, 46(25), 47224725.

45. Bokare, A. D., \& Choi, W. (2014). Review of iron-free Fenton-like systems for activating $\mathrm{H} 2 \mathrm{O} 2$ in advanced oxidation processes. Journal of hazardous materials, 275, 121-135.

46. Sultana, B., Anwar, F. and Przybylski, R. (2007). Antioxidant activity of phenolic components present in barks of Azadirachta indica, terminalia arjuna, acacia nilotica and eugenia jambolona lam, trees. Food chemistry, 104 (3),1106-1114

47. Giorgio, M., Trinei, M., Migliaccio, E., and Pelicci, P. G. (2007). Hydrogen peroxide: a metabolic by-product or a common mediator of ageing signals? Nature reviews Molecular cell biology, 8(9), 722.

48. Sies, H. (2014). Role of metabolic $\mathrm{H}_{2} \mathrm{O}_{2}$ generation Redox signaling and oxidative stress. Journal of Biological Chemistry, 289(13), 87358741

49. Ballinger, S. W., Patterson, C., Yan, C. N., Doan, R., Burow, D. L., Young, C. G., \& Runge, M. S. (2000). Hydrogen peroxide-and peroxynitrite-induced mitochondrial DNA damage and dysfunction in vascular endothelial and smooth muscle cells. Circulation research, 86(9), 960-966.

50. Watt, B. E., Proudfoot, A. T., and Vale, J. A. (2004). Hydrogen peroxide 
Dehariya, et al.

poisoning. Toxicological Reviews, 23(1), 51-57.

51. Park, S., You, X., \& Imlay, J. A. (2005). Substantial DNA damage from submicromolar intracellular hydrogen peroxide detected in Hpxmutants of Escherichia coli. Proceedings of the National Academy of Sciences, 102(26), 9317-9322.

52. Khansari, N., Shakiba, Y., \& Mahmoudi, M. (2009). Chronic inflammation and oxidative stress as a major cause of age-related diseases and cancer. Recent patents on inflammation and allergy drug discovery, 3(1), 73-80.

53. Ye, J. X., Liang, R. X., Wang, L., Yang, B., and An, R. S. (2008). ESR study and protection of water extract of Carthamus tinctorius on ox-LDL induced injury in rat cardiac microvascular endothelial cell. Zhongguo Zhong yao za zhi= Zhongguo zhongyao zazhi= China journal of Chinese Materia Medica, 33(21), 2513-2517.

54. Choi, C. W., Kim, S. C., Hwang, S. S., Choi, B. K., Ahn, H. J., Lee, M. Y., and Kim, S. K. (2002). Antioxidant activity and free radical scavenging capacity between Korean medicinal plants and flavonoids by assay- guided comparison. Plant science, 163(6), 1161-1168.

55. Yang, C. S., Landau, J. M., Huang, M. T., \& Newmark, H. L. (2001). Inhibition of carcinogenesis by dietary polyphenolic compounds. Annual Review of Nutrition, 21(1), 381-406.

56. Parr, A. J., and Bolwell, G. P. (2000). Phenols in the plant and in man. The potential for possible nutritional enhancement of the diet by modifying the phenols content or profile. Journal of the Science of Food and Agriculture, 80(7), 985-1012.

57. Croft, K. D. (1998). The Chemistry and Biological Effects of Flavonoids and Phenolic Acids. Annals of the New York Academy of Sciences, 854(1), 435-442.

58. Dudonne, S., Vitrac, X., Coutiere, P., Wollez, M. and Merilion, J.M. (2009). Comparative study of antioxidant properties and total phenolic content of 30 plant extracts of industrial interest using DPPH, ABTS, FRAP,SOD and ORAC assays. Journal of agriculture and food chemistry, 57,1768-1774. 